\title{
A Rare Cause of Intestinal Obstruction in Infants: Ileum Duplication Cyst
}

\author{
Dr. Pratima Kujur ${ }^{1}$, Dr. Shashikala Kosam ${ }^{2}$, Dr. Girish Kumar Suman ${ }^{3}$ \\ ${ }^{1}$ Professor and Head Department of Pathology, Pt. Jawaharlal Nehru Memorial Medical College, Raipur (C.G.) India, 492001 \\ ${ }^{2}$ Assistant Professor, Department of Pathology, Pt. Jawaharlal Nehru Memorial Medical College, Raipur (C.G.) India, 492001
}

${ }^{3}$ Second Year PG, Resident Department of Pathology, Pt. Jawaharlal Nehru Memorial Medical College, Raipur (C.G.) India, 492001

\begin{abstract}
Duplication cyst is a rare congenital anomaly presenting in pediatric patients that is most commonly seen in the ileum. It was first described by Wendel. Though they are more often observed in the small intestine, DCs can also more rarely be rectal, duodenal, gastric, and thoraco-abdominal. They have an incidence of 1/100,000. A 5 day old girl was admitted to our hospital for investigation of progressive abdominal distension and biliary vomiting. USG and CT-SCAN finding shows a large thin walled intra peritoneal welldefined cystic lesion occupying whole of the abdominal cavity. Microscopic examination of cyst shows features of enteric duplication cyst.
\end{abstract}

Keywords: enteric duplication cyst, infant, intestinal obstruction, perforation, malignancy

\section{Introduction}

Duplication cysts (DCs), which may have either a spherical cystic or a tubular structure, are among the more rarely observed of congenital malformations of the gastrointestinal system (GIS). The first DC was described in 1733 by Calderin, followed by another in 1884 by Fitz. In 1937, Ladd defined DCs as having the following three properties: (a) the cyst is surrounded by smooth muscle, (b) the cyst must contain the GIS mucosa from which it takes its own origin, and (c) the cyst must have a wall in common with the anatomic region in which it is found [1]. DCs can be found anywhere in the GIS, from the mouth to the anus.

Though they are more often observed in the small intestine, DCs can also more rarely be rectal, duodenal, gastric, and thoraco-abdominal. They have an incidence of $1 / 100,000$ [2]. They become symptomatic depending on their localization. They generally evidence signs of compression. Complications include bleeding into the cyst, obstruction, perforation, fistulization, and, rarely, malignancy [3].

\section{Case}

A 5 day old girl was admitted to our hospital for investigation of progressive abdominal distension and biliary vomiting. Ultrasonography shows large abdominal cystic lesion with double layer wall and internal echoes occupying whole abdomen, not communicating with lumen of bowel or stomach .CT scan finding shows a large thin walled intra peritoneal well-defined cystic lesion occupying whole of the abdominal cavity and displacing abdominal structure periphery.Features suggestive of Enteric Duplication Cyst.

Histopathological evaluation

- Gross findings $-\mathrm{A}$ cystic swelling of size $14 \times 8 \mathrm{~cm}$. Outer surface smooth, grey white to grey brown, cut surface- brownish with presence of some focal grey white area in between. Mucosal linings are seen but they are not very prominent.

- Microscopic findings-Cyst lined by ilealmucosa.Wall contained smooth muscle arranged in circular and longitudinal fashion.
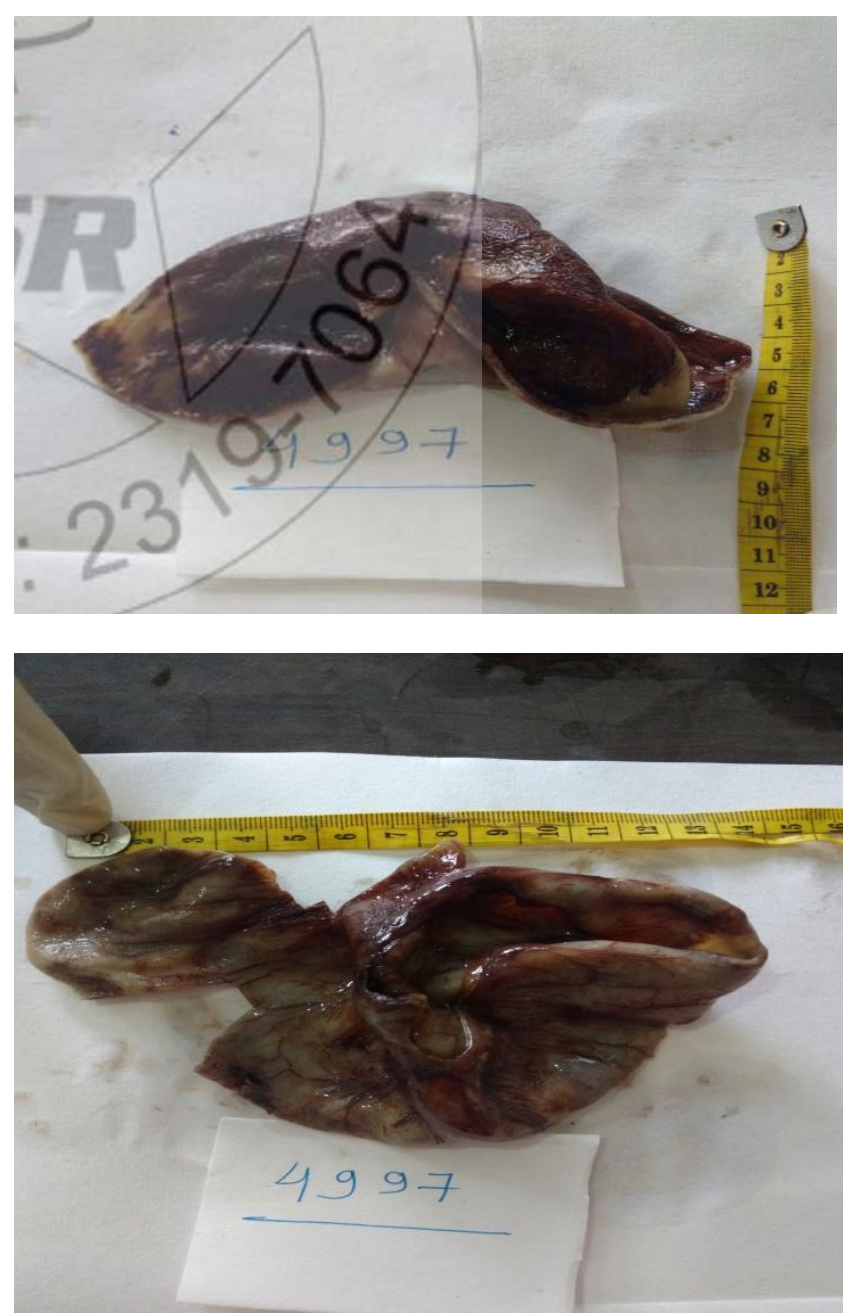


\section{International Journal of Science and Research (IJSR) \\ ISSN (Online): 2319-7064}

Index Copernicus Value (2015): 78.96 | Impact Factor (2015): 6.391

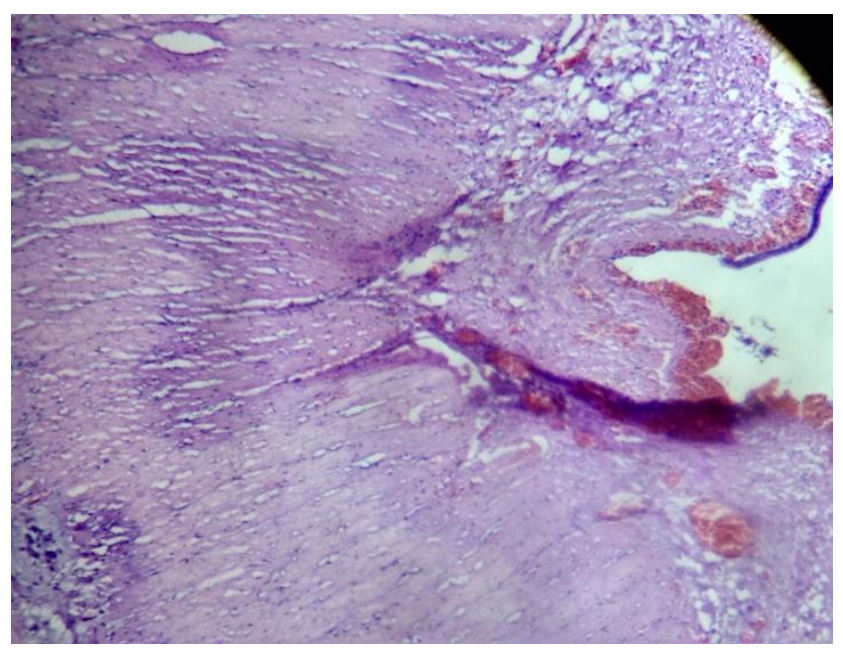

\section{Discussion}

Duplication cyst is a rare congenital anomaly presenting in pediatric patients that is most commonly seen in the ileum [4]. It was first described by Wendel[5]. There have been few cases of its presentation in adults reported ever since. The condition is usually seen in males. A number of etiological theories have been suggested, of which persistence of the fetal gut diverticula or "aborted Gemini", and defect in the recanalization of the primitive gut are the most accepted. Any failure in the transition process of the intestinal tract from solid to tubular state between 6 and 8 weeks of intrauterine life may lead to the formation of duplication cysts [6]. These cysts have an outer muscular lining with an inner gastrointestinal lining. They are generally intra-abdominal; however intra-thoracic and thoraco-abdominal duplication cysts are also encountered. As these congenital malformations share a common blood supply with adjoining gastrointestinal tract, its complete excision may demand resection-anastomosis of adjoining gastrointestinal tract.

Duplication cysts are most commonly diagnosed in early life between 1- 2 years of age with intestinal obstruction or a palpable mass. In adults, the condition may be left undiagnosed. Commonly, they present with vague abdominal complaints. However, they may also present acutely in the setting of obstruction, hemorrhage or perforation [7]. Due to the risk of progression from benign pathology to malignancy or other complication, surgery should be offered, preferably minimally invasive approach to all symptomatic or asymptomatic patients. Rarely, the cyst may cause a fistula with the adjoining structure [8]. Duplication cysts may be associated with malrotation, esophageal duplication and vertebral anomalies [5] and [9]. A cyst may be termed as a true duplication cyst if it fulfills the three criteria: attachment to any part of the gastrointestinal tract, lined by any gastrointestinal epithelium and containing smooth muscle in its wall [10]. It may be cystic or tubular. Cystic duplication cysts are commoner. They do not communicate with the bowel, but may share a common wall and blood supply. Tubular duplication cysts communicate with the intestinal lumen [10].
The preoperative diagnosis can be made on USG and CT The cystic nature of the lesion is visible on USG. The diagnosis can be confirmed even on USG if the characteristic inner echogenic layer and the hypoechogenic outer muscular layer can be defined [4]. Kumar et al. proposed a ,five layered cyst wall ${ }^{\text {ce }}$ sign seen on ultrasonography delineating the outermost hyperechoic serosa, hypoechoicmuscularispropria, hyperechoicsubmucosa, hypoechoicmuscularis mucosa and the innermost hyperechoic mucosa [11]. CT scan shows the fluid filled cystic structures or the tubular structures with slightly enhancing walls in close proximity to the small bowel. Endoscopic ultrasound may also be used for the evaluation of duplication cysts. Surgery is imperative in symptomatic patients. There is no data available for the management in asymptomatic patients. However, it is deemed beneficial to surgically treat these cases due to the possible malignant change in duplication cysts [12]. Surgery entails resecting the involved bowel, however, in completely isolated cysts; excision of these may be done without resecting the bowel. Ileal duplication cysts are known to show heterotropic gastric mucosa [13].

\section{References}

[1] T. Scheye, G. Vanneuville, P. Dechelotte, C. QueroyMalamenaide, and B. Aufauvre, "Duplication of the digestive tract in children. Apropos of 12 cases," Annales de Chirurgie, vol. 49, no. 1, pp. 47-55, 1995.

[2] M. H. Okur, M. S. Arslan, S. Arslan et al., "Gastrointestinal tract duplications in children," European Review for Medical and Pharmacological Sciences, vol. 18, no. 10, pp. 1507-1512, 2014. View at Google Scholar .

[3] N. Nakazawa, T. Okazaki, and T. Miyano, "Prenatal detection of isolated gastric duplication cyst," Pediatric Surgery International, vol. 21 , no. 10, pp. 831-834, 2005.

[4] Kuo H.C., Lee H.C., Shin C.H., Sheu J.C., Chang P.Y., Wang N.L. Clinical spectrum of alimentary tract duplication in children. ActaPaediatr. Taiwan. 2004;45(2):85-88. [PubMed]

[5] Kim Y., Kim Y., Jeong Y., Moon W., Gwak H. Ileal duplication cyst: y-configuration on in vivo sonography. J. Pediatr. Surg. 2009;44(7):1462-1464. [PubMed]

[6] Ríos S.S., Noia J.L., Nallib I.A. Adult gastric duplication cyst: diagnosis by endoscopic ultrasoundguided fine-needle aspiration (EUS-FNA) Rev. Esp. Enferm. Dig. 2008;100(9):586-590. [PubMed]

[7] Teele R.L., Henschke C.I., Tapper D. The radiographic and ultrasonographic evaluation of enteric duplication cysts.Pediatr.Radiol.1980;10(1):9-14. [PubMed]

[8] Shah A., Du J., Sun Y., Cao D. Dynamic change of intestinal duplication in an adult patient: a case report and literature review. Case Rep. Med. 2012;2012:1-3. [PMC free article][PubMed]

[9] Islah M.A.R., Hafizan T. Perforated ileal duplication cyst presenting with right iliac fossa pain mimicking perforated appendicitis. Med. J. Malaysia. 2008;63(1):63-64. [PubMed]

[10] Srivastava P., Gangopadhyay A., kumar V., Upadhyaya V., Sharma S., Jaiman R. Noncommunicating isolated 


\section{International Journal of Science and Research (IJSR) \\ ISSN (Online): 2319-7064}

Index Copernicus Value (2015): 78.96 | Impact Factor (2015): 6.391

enteric duplication cyst in childhood. J. Pediatr. Surg. 2009;44(7):e9-e10. [PubMed]

[11]Habib K., Khan M., Sheehan A., Coker O. Adenocarcinoma in ileal duplication cyst: case report and review of literature. Open Med. 2009;4(3)

[12]Kumar D., Ramanathan S., Haider E., Khanna M., Otero C. Gastroenterology Revisiting the forgotten sign: five layered gut signature and Y configuration in enteric duplication cysts on high resolution ultrasound. J. Gastroenterol. Hepatol.2015;30(7) 1111-1111. [PubMed]

[13] Gümüs M., Kapan M., Gümüs H., Önder A., Girgin S. Unusual noncommunicating isolated enteric duplication cyst in adults. Gastroenterol. Res. Pract. 2011;2011:1-3. [PMC free article] [PubMed] 